Disponível em:

http://editora.unoesc.edu.br/index.php/race

Race, Joaçaba, v. 14, n. 2, p. 797-824, maio/ago. 2015

\title{
CONSUMO NA BAIXA RENDA: INFLUÊNCIA DOS VALORES DE COMPRA HEDÔNICO E UTILITÁRIO NO ENDIVIDAMENTO
}

\section{Consumption by low-income people: influence of the pleasurable and the utilitarian purchase values on the indebtedness}

Felipe Gerhard

E-mail: felipegerhard.rns@gmail.com Mestre em Administração pela Universidade Estadual do Ceará; Graduado em Administração pela Universidade Estadual do Ceará.

Thiago Matheus de Paula Sousa

E-mail: thiagomatheus.rns@gmail.com Graduando em Ciências Econômicas pela Universidade Federal do Ceará.

Lucas Lopes Ferreira de Souza

E-mail: lucaslfsouza@hotmail.com Mestre em Administração pela Universidade Estadual do Ceará; Graduado em Administração pela Universidade Estadual do Ceará.

Helder Araujo de Carvalho

E-mail: helder_72@yahoo.com.br

Graduado em Administração pela Faculdade de Ensino Superior de Floriano; mestrando em Administração pela Universidade Estadual do Ceará;

\section{Verónica Ligia Peñaloza Fuentes}

E-mail: vero.pf0@gmail.com

Pós-Doutora pela Universidad de La Frontera; Doutora e Mestre em Economia pela Universidade de São Paulo; Professora do Curso de Mestrado Acadêmico em Administração da Universidade Estadual do Ceará. Endereço para contato: Avenida Paranjana, 1700, Campus do Itaperi, Aldeota, 60740-020, Fortaleza, Ceará, Brasil.

Artigo recebido em 30 de setembro de 2014. Aceito em 23 de janeiro de 2015. 


\title{
Resumo
}

O presente estudo teve por objetivo analisar os valores de consumo hedônico e utilitário, bem como a influência desses valores sobre a conduta financeira dos consumidores de baixa renda. Para tal, foi realizada uma pesquisa descritiva, de natureza quantitativa, viabilizada por meio de um estudo de corte transversal único, cuja consecução foi obtida mediante a aplicação de um survey, no qual foram entrevistados 528 indivíduos. Para a análise dos dados, foram utilizados módulos de estatística descritiva e a técnica de modelagem de equações estruturais. Os principais resultados do estudo indicam que a maior parte dos entrevistados está endividada, apresentando maior valor hedônico de compra. Também se destaca o fato de o arquétipo teórico construído com base na literatura não ter alcançado valores de ajuste aceitáveis, demonstrando, além de uma frágil sustentação teórica, um baixo rigor científico das escalas utilizadas de atitude à dívida. Após a reespecificação do modelo teórico, observouse que a presença hegemônica do valor de consumo hedônico em um indivíduo indica mais eficazmente se ele de fato se endivida.

Palavras-chave: Baixa renda. Endividamento. Consumo hedônico. Consumo utilitário.

\section{Consumption by low-income people: influence of the pleasurable and the utilitarian purchase values on the indebtedness}

\begin{abstract}
This paper aimed to analyze the values of hedonic and utilitarian consumption, as well as the influence of these values on the financial behavior of low-income consumers. For such, a descriptive research, with quantitative nature, was carried out through a study of single cross section, whose achievement was obtained by applying a survey, in which 528 individuals were interviewed. For data analysis, modules of descriptive statistics and structural equation modeling were used. The main results of the study indicate that the majority of respondents are in debt, with higher hedonic value of purchase. It is also important to highlight the fact that the theoretical archetype built based on literature did not reach acceptable fit values; it demonstrates, beyond a weak theoretical support, a low scientific rigor of the scales used in attitude to debt. After the modification of the theoretical model, it was observed that the hegemonic presence of the hedonic consumption value in an individual indicates more effectively if he/she indeed becomes indebted.
\end{abstract}

Keywords: Low income. Indebtedness. Hedonic consumer. Utility consumer.

\section{INTRODUÇÃO}

Apesar de o crescente interesse acadêmico pela área de comportamento do consumidor de baixa renda, advindo principalmente após o estudo de Prahalad e Hart (2002), evidenciar o grande potencial de consumo detido por esse segmento, 
o arcabouço teórico constituído pelos estudos relacionados ao tema ainda é insípido (MATTOSO, 2010; HEMAIS; CASOTTI; ROCHA, 2013).

Segundo Hammond et al. (2007), os consumidores de baixa renda diferenciam-se em vários aspectos, e muitos subsegmentos podem coexistir, visto que os padrões de consumo se modificam de acordo com a região geográfica ou nível de renda. Apesar de os limites da baixa renda variarem de país para país, ainda de acordo com os autores, estima-se que a maioria da população mundial, cerca de quatro bilhões de pessoas, vivam em relativa ou total pobreza, com renda anual inferior a US\$ 3.000. Suas rendas diárias em dólar são menores do que US\$ 3,35 no Brasil, US\$2,11 na China, US\$ 1,89 em Gana e US\$ 1,56 na Índia. Porém, juntos possuem substancial poder de compra, uma vez que constituem um mercado consumidor global de US\$ 5 trilhões. Estima-se que 50\% do poder de compra das economias emergentes está contido nesse segmento (HAMMOND et al., 2007).

Segundo a Pesquisa Nacional de Inadimplência do Consumidor, realizada pela Confederação Nacional do Comércio de Bens, Serviços e Turismo (CNC) (2014), o percentual de famílias brasileiras endividadas entre cheque pré-datado, cartões de crédito, carnês de lojas, empréstimos pessoais, prestações de carro e seguros vem crescendo desde 2010. De acordo com o Instituto, o quadro de endividamento dos consumidores brasileiros é grave: $63,4 \%$ dos entrevistados estão endividados, 19,5\% possuem dívidas em atraso e 6,5\% não terão condições de pagar suas contas no futuro.

No que se refere ao comportamento de indivíduos de baixa renda, o desenvolvimento da teoria do consumo possibilitou o surgimento de duas vertentes diametralmente opostas: a primeira define como irracional o comportamento de compra dos pobres, apontando-os como incapazes de cuidar adequadamente de suas rendas e interesses como consumidores (CAPLOVITZ, 1963; KARNANI, 2007); enquanto a segunda considera as decisões de consumo tomadas por esses indivíduos dotadas de alto grau de racionalidade (HILL; STEPHENS, 1997; WILLIAMS; WINDEBANK, 2001; PRAHALAD; HART, 2002; HILL, 2008). Dessa forma, pode-se inferir que há uma ausência de consenso quanto ao perfil de consumo e à atitude relacionada à dívida desses consumidores.

Contudo, embora o crescimento do endividamento em escala mundial seja atribuído, em geral, a questões de limitação de renda, associar a dívida a fatores exclusivamente financeiros é uma abordagem limitada, uma vez que tal fenômeno transcende a aspectos meramente econômicos (DENEGRI, 2007; LUSARDI; MITCHELL, 2007; DEAN et al., 2013). Dessa forma, é necessário que se perscrutem 
atributos que ultrapassem explicações monetárias, atingindo dimensões intrínsecas ao próprio consumidor. Complementarmente, Hemais, Casotti e Rocha (2013) discorrem ainda sobre a necessidade de se expandir essa discussão para englobar a baixa renda, visto que ainda pouco se conhece sobre as características que envolvem o consumo e o endividamento nesse segmento.

Desse modo, o propósito central deste trabalho é analisar, em uma feira livre e em um pequeno varejo, os valores de compra hedônico e utilitário e a conduta financeira dos consumidores de baixa renda, bem como a influência desses valores sobre a conduta financeira desses indivíduos. Cumpre salientar que as relações causais entre os valores de consumo e a atitude ao endividamento não foram anteriormente perscrutadas. As relações levantadas no estudo baseiam-se nas dimensões conceituais que os construtos possuem em comum.

Este trabalho estrutura-se em cinco seções além desta introdução. Inicialmente, abordar-se-á o contexto empírico, com uma breve contextualização sobre a baixa renda; logo após, apresenta-se uma breve revisão de estudos relacionados aos valores de consumo e ao endividamento, com atenção especial aos voltados à baixa renda. Em seguida, serão tratados os principais aspectos metodológicos. Por fim, serão aferidos os resultados e apresentadas as conclusões e as recomendações para pesquisas futuras.

\section{BAIXA RENDA}

Os estudos versados à baixa renda, por muitas vezes, apresentam limitações em sua análise, em grande parte referente à relatividade em sua estratificação. De acordo com Prahalad (2006), por exemplo, a segmentação da baixa renda alienase à sua posição na pirâmide econômica. Pertencem aos estratos inferiores, a denominada base da pirâmide, as pessoas com rendimentos diários de até dois dólares (PRAHALAD, 2006). Rocha e Silva (2008), contudo, ressalvam que se deve ter cautela ao se basear em tal definição, uma vez que, segundo tais parâmetros, somente $18 \%$ da população brasileira estaria inserida nesse contexto.

De forma similar, no Brasil, a baixa renda é estratificada, amiúde, de forma descontínua. O Critério de Classificação Econômica Brasil, elaborado pela Associação Brasileira de Empresas de Pesquisa (ABEP), por seu turno, considera a acumulação de bens e o grau de instrução do chefe do domicílio para estratificar a população, cuja divisão é estabelecida em oito classes econômicas: A1, A2, B1, 
B2, C1, C2, D e E (ABEP, 2012). A Pesquisa Nacional por Amostra de Domicílios (PNAD), realizada pelo Instituto Brasileiro de Geografia e Estatística (IBGE), ademais, considera a renda média mensal domiciliar para a divisão social, a qual é distribuída em seis classes (IBGE, 2009).

Em vista desse impasse, o Centro de Excelência em Varejo da Fundação Getúlio Vargas (CEV-FGV) (2008) delimitou o constructo baixa renda no Brasil àqueles que pertencem às classes $\mathrm{D}$ e $\mathrm{E}$, que, embasado na classificação do IBGE (2009), compreende famílias com renda mensal de até cinco salários mínimos. De acordo com o instituto, 91 milhões de brasileiros se enquadrariam no estrato de baixa renda, cerca de $40 \%$ da população. Como é possível observar, tais divergências acerca da baixa renda indicam como é importante conhecer as delimitações de classe econômica para se compreender o real comportamento do consumidor de baixa renda.

Acerca de pouco mais de uma década, a ideia de consumo era veiculada a uma visão elitista, cuja representatividade era marcada pela alta classe. Os indivíduos de baixa renda sequer eram vistos como consumidores, pois o signo da carência material estava tradicionalmente relacionado às classes menos abastadas (BARROS; ROCHA, 2007). Percebe-se, pois, que o consumo na baixa renda fora por muito renegado pela ótica acadêmica, cujos estudos, na maior parte dos casos, tomaram a burguesia e a aristocracia como foco, deixando um abismo no que se refere ao consumo das classes populares.

No entanto, empresas e pesquisadores passaram recentemente a estudar mais a fundo esse campo social emergente. Embora a renda média desses consumidores seja inferior às demais classes, seu poder de compra total é elevado, sobretudo em razão da quantidade de indivíduos que se encontram nessa situação (PRAHALAD, 2006). Destarte, as ações mercadológicas voltadas à baixa renda apresentam-se de forma favorável a uma oportunidade de crescimento, visto que a possibilidade de consumir produtos cujo acesso era antes restrito às classes mais abastadas permite aos consumidores de baixa renda passar a admirar empresas que se empenham em vender às classes mais pobres (HEMAIS; CASOTTI; ROCHA, 2013).

Segundo Rocha e Silva (2008), o aumento no interesse pelo comportamento dos consumidores pobres advém do substancial aumento do consumo em países emergentes, como o Brasil, já que o poder aquisitivo de suas populações aumentou (ROCHA, 2009). Por conseguinte, a possibilidade de se inserir na sociedade de consumo, isto é, a facilidade de poder comprar produtos que antes eram restritos às classes mais abastadas, desperta nos consumidores de baixa renda um sentimento de admiração pelas empresas que têm seu enfoque nas camadas econômicas mais abastadas. 


\section{SOCIEDADE DO CONSUMO, VALORES DE COMPRA E ENDIVIDAMENTO}

As primeiras abordagens sobre o consumo foram tratadas sob o enfoque da teoria econômica tradicional, em que, de acordo com os seus postulados, o consumidor faria suas escolhas de forma racional, eficiente e objetiva, procurando sempre o menor dispêndio monetário. Contudo, de acordo com Veblen (1915), o consumo seria um fenômeno ilógico e demasiado complexo para ser enquadrado em modelos econômicos tradicionais, logo, deveria ser visto como algo fora desses padrões. Ele satirizava a cultura pecuniária de seu tempo, no qual o status era baseado principalmente sobre a exibição da riqueza, e preconizou a tendência a se imitar os ricos pelos mais pobres. O ócio, para o autor, teria sido substituído pelo consumo conspícuo como a atividade que transmitiria características pessoais de cada indivíduo a seus pares.

Com efeito, em meados do século XX, Warner, Meeker e Eells (1949) ratificaram a ideia de complexidade do consumo ao relacionar o comportamento do consumidor à classe social à qual pertence. Esse comportamento é uma importante expressão que evidencia o status social do indivíduo. Cada classe possui motivações e interesses de compra únicos que as distinguem umas das outras. Desse modo, as classes sociais interfeririam de forma direta no comportamento de consumo por serem, além de categorias de status, grupos motivacionais. Bourdieu (2011) expande a discussão sobre o consumo ao conceituá-lo como elemento estruturante da imagem simbólica do homem social. O autor anuía à ideia de Warner, Meeker e Eells (1949) ao entender a estrutura social como um sistema hierarquizado, definido de acordo com a propriedade de capitais materiais ou simbólicos retidos pelo indivíduo. Bourdieu (2011) elucida ainda os componentes constituintes do cabedal de qualquer ator social, que seriam os capitais econômico, cultural, social e simbólico. O volume de aquisição desses elementos definiria a ordem social de seus possuidores, além de servir também como marco discriminatório.

Outros autores continuaram a discussão sobre o tema dentro das ciências sociais, todavia, comum a todos está a ideia de que cultura e valores sociais estão intimamente atrelados ao consumo. Ressalta-se, contudo, a contribuição de Baudrillard (2006) para a ampliação desse debate. O autor conceitua consumo como um simulacro, um arquétipo limitado concebido pelos próprios consumidores 
como uma forma de atingir uma felicidade efêmera. Segundo o autor, reproduzir a felicidade por meio do consumo desenvolveria uma alienação estrutural no indivíduo, capaz de eclipsar as demais esferas de sua vida, relegando-as a segundo plano, desenvolveria uma espécie de cegueira orientada, uma lógica que vincula e direciona todos os aspectos de sua senda ao desempenho da atividade de consumir.

Consonante com os até então novos conceitos evidenciados sobre o consumo, Holbrook e Hirschman (1982) definem como hedônica a visão do consumo motivada por aspectos multissensoriais, motivos e fantasias do consumidor. Analisados por essa vertente, os produtos (desejos de consumo) passam a ser percebidos como símbolos subjetivos. A compra hedônica não traz consigo o sentido negativo de trabalho árduo, difícil de ser realizado (BABIN; DARDEN; GRIFFIN, 1994; HAUSMAN, 2000); esse tipo de consumo está relacionado ao valor percebido da experiência de compra pelo consumidor, ou seja, fatores subjetivos que variam de acordo com o contexto de cada um. A decisão de compra é apenas um pequeno componente entre todos os envolvidos na experiência de consumo em geral (HOLBROOK; HIRSCHMAN, 1982). O endividamento relaciona-se intimamente com a dimensão hedônica de consumo, uma vez que são explicados por fatores comuns a ambos, como materialismo, consumismo, compra por prazer e consumo simbólico (LIVINGSTONE; LUNT, 1992; DENEGRI, 2007; TRINDADE et al., 2010).

Da mesma forma, para Rocha (2005), a ideologia hedonista preconiza o consumismo, desenvolvendo uma forma de promover a cultura de consumo, fortemente presente em nossa sociedade (BAUDRILLARD, 2002). Com efeito, Lipovetsky (2007) e Lipovetsky e Serroy (2011) representam uma das contribuições teóricas mais recentes sobre o fenômeno de sociedade de consumo. Os autores criam o conceito de sociedade de hiperconsumo para retratar a sociedade atual, abordando o ato de consumir não mais como algo que apenas possibilita distinção social, mas que permitiria viver um processo de individualização da experiência do consumo, mediante a redescoberta de uma herança mitológica de profusão de sentimentos e bens materiais. Estaríamos, para os autores, revivendo o ethos da alegria, que recria a cultura cotidiana ao prestar culto às sensações, prazeres corpóreos e volúpias do presente. Destarte, toda a sociedade, denominada sociedade do hiperconsumo, estaria estruturada para atender a essas supostas necessidades advindas do hiperconsumidor. Em nome dessa felicidade paradoxal, seria pensado e erigido todo o sistema econômico de produção de bens, prestação de serviços e as mídias e, até mesmo, a educação e a urbanização social. 
Por outro ladro, a dimensão de consumo utilitária orienta os consumidores que buscam o cumprimento de objetivos e menores riscos, conforme aduzem Batra e Ahtola (1991). Os valores de compra utilitários emergem quando, em termos racionais, a execução da compra é completada com sucesso e eficiência. Nesse sentido, segundo os autores, o utilitarismo sobrevém de resultados relativamente tangíveis da experiência de compra, como uma aquisição eficiente de um produto. Portanto, o discurso utilitário é essencialmente racional e funcional, e representa, pois, o trabalho de compra bem feito. O valor utilitário em uma compra é baseado na utilidade que esta possui para o consumidor, se o bem ou serviço demandado atende de fato às suas necessidades, sendo esse valor o reflexo da aquisição de produtos ou serviços que ocorreu de forma eficiente como uma tarefa orientada (BABIN; DARDEN; GRIFFIN, 1994). Dessa forma, a atitude contrária ao endividamento e o valor de consumo utilitário relacionar-se-iam pelo fato de a dimensão utilitária vincular-se à execução de uma compra com eficiência, baseando-se na racionalidade e no atendimento de necessidades concretas (LIVINGSTONE; LUNT, 1992; DENEGRI, 2007; TRINDADE et al., 2010).

Contudo, autores como Bardhi e Arnould (2005) e Lopes et al. (2010) concordam que o consumo utilitário e o hedônico podem coexistir em uma experiência de compra, pois, mesmo tratando-se de valores diferentes, entende-se que eles não são excludentes entre si, apenas abordam características distintas. A abordagem utilitária reporta-se a aspectos racionais, objetivos e econômicos, enquanto a hedônica se foca em características psicológicas, simbólicas e emotivas do consumo (BABIN; DARDEN; GRIFFIN, 1994). Para Rocha (2005), em razão da intensidade do fenômeno de consumir, todos possuem o desejo de consolidá-lo e buscar a felicidade por meio desse ato, independentemente da classe social em que o indivíduo se encontre.

Com base no desenvolvimento da teoria do consumo, Rocha e Silva (2008) destacam dois enfoques distintos que começam a aparecer desde o início da década de 1960, especificamente em relação ao consumo dos pobres. O primeiro enfoque é inaugurado por Caplovitz (1963), que define como irracional o comportamento de compra dos pobres, apontando-os como incapazes de cuidar adequadamente de suas rendas e interesses como consumidores, além da possibilidade de serem facilmente enganados pelas agressivas estratégias de marketing das empresas (KARNANI, 2007). O outro enfoque é compartilhado por autores como Hill e Stephens (1997), Williams e Windebank (2001), Prahalad e Hart (2002) e Hill (2008), que consideram as decisões de consumo tomadas por indivíduos de rendas menos abastadas, em um contexto de limitações materiais, dotadas de alto grau de racionalidade. 
No que se refere a essa discussão sobre a capacidade dos indivíduos de baixa renda de gerir seus orçamentos, a pobreza tem sido frequentemente atribuída ao fenômeno do aumento no endividamento dos consumidores ao redor do mundo, visto que seria uma das condições elementares que acarretam em dificuldade para as famílias honrarem as dívidas contraídas a altas taxas de juros (JOO; GRABLE, 2004; LEGGE; HEYNES, 2009; STEENING et al., 2010).

Contudo, associar a dívida do consumidor simplesmente à sua renda é uma abordagem limitada. O endividamento é um fenômeno que ultrapassa os aspectos meramente econômicos (DENEGRI, 2007; LUSARDI; MITCHELL, 2007; DEAN et al, 2013). Diante disso, os estudos atuais sobre o endividamento vêm associando-o a outros fatores psicológicos que influenciam as decisões de consumo, como materialismo, autoestima, lócus de controle, comportamento em relação ao risco, hábitos de uso do dinheiro, estilo de vida, transtornos mentais, valores pessoais, entre outros (LIVINGSTONE; LUNT, 1992; KIDWELL; TURRISI, 2003; NORVILITIS; SZABLICKI; WILSON, 2006; STONE; MAURY, 2006; DENEGRI, 2007). Para tais estudos, valores intrínsecos são os reais responsáveis pelo endividamento, e não questões de ordem puramente econômica.

Com efeito, os valores hedônico e utilitário, porquanto representem características psicológicas que orientam o comportamento de compra dos indivíduos, são capazes de predizer a inclinação do indivíduo ao endividamento. Dessa forma, relacionando-se os valores de compra hedônico e utilitário à atitude ao endividamento e, por fim, ao endividamento de fato, são erigidas as hipóteses de pesquisa embasando-se nas acepções teóricas levantadas na literatura.

- H1: há relação positiva entre valor de consumo hedônico e a atitude favorável ao endividamento do consumidor de baixa renda.

- H2: há relação positiva entre valor de consumo utilitário e a atitude contrária ao endividamento do consumidor de baixa renda.

- H3: há relação positiva entre a atitude favorável ao endividamento e o endividamento relatado pelo consumidor de baixa renda.

- H4: há relação negativa entre a atitude contrária ao endividamento e o endividamento relatado pelo consumidor de baixa renda.

Para facilitar a compreensão das relações causais construídas, e como síntese das hipóteses de pesquisa a elas relacionadas, o Esquema 1 apresenta o modelo teórico proposto. 


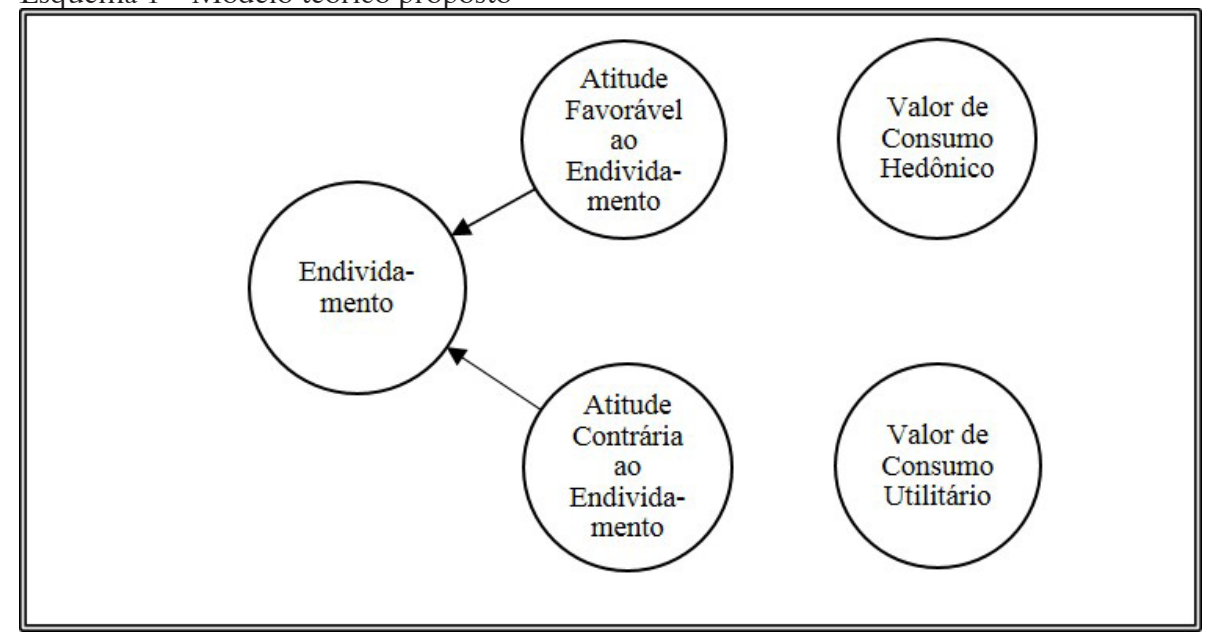

Fonte: os autores.

\section{PROCEDIMENTOS METODOLÓGICOS}

Para atender aos propósitos da pesquisa, empreendeu-se um estudo descritivo, de natureza quantitativa, realizado por meio de um estudo de corte transversal único, cuja consecução foi obtida por meio da aplicação de um survey (HAIR et al., 2009; MALHOTRA, 2006).

Para investigar as relações propostas pelas hipóteses de pesquisa, foi empregada a modelagem de equações estruturais (KLINE, 2005; ARBUCKLE, 2009; HAIR et al., 2009; TABACHNICK; FIDELL, 2011), por meio de uma modelagem de desenvolvimento incremental de modelos (HAIR et al., 2009; TABACHNICK; FIDELL, 2011), uma vez que se tem o objetivo de melhorar o modelo teórico erigido da literatura a partir da modificação dos modelos estrutural e de mensuração (ANDERSON; GERBING, 1988; HAIR et al., 2009; BYRNE, 2013), resultando em um modelo causal mais adequado.

O instrumento de pesquisa foi composto por 20 variáveis, que correspondiam às escalas de Babin, Darden e Griffin (1994) e Trindade et al. (2010) e um item sobre endividamento, em escala de Likert de sete pontos. A primeira escala é formada por 13 itens, sete variáveis sobre valor de compra hedônico e seis variáveis referentes ao valor de compra utilitário; a segunda escala é composta por seis itens, três variáveis relacionadas à atitude favorável ao endividamento e três variáveis referentes à atitude contrária ao endividamento. Os construtos e suas respectivas variáveis são elencados 
no Quadro 1. Também foram abordadas questões de caráter socioeconômico, como: sexo, renda, nível de escolaridade, bairro em que reside, entre outras.

Quadro 1 - Variáveis, construtos e autores do instrumento de pesquisa

\begin{tabular}{|c|c|c|}
\hline Nome & Variáveis & Autores \\
\hline \multicolumn{2}{|c|}{ Valor de compra hedônico } & \multirow{8}{*}{$\begin{array}{l}\text { Babin, } \\
\text { Darden } \\
\text { e Griffin } \\
(1994)\end{array}$} \\
\hline HEDO_1 & Eu me diverti fazendo esta compra. & \\
\hline HEDO_2 & Eu fiz esta compra porque quis e não por obrigação. & \\
\hline HEDO_3 & $\begin{array}{l}\text { Comparando com outras coisas que eu poderia ter feito, o } \\
\text { tempo gasto comprando este produto foi muito mais agradá- } \\
\text { vel. }\end{array}$ & \\
\hline HEDO_4 & Esqueci os meus problemas enquanto estive na Feira. & \\
\hline HEDO_5 & Fazer esta compra foi uma verdadeira distração para mim. & \\
\hline HEDO_6 & $\begin{array}{l}\text { Estar no Beco foi um jeito muito agradável de passar o } \\
\text { tempo. }\end{array}$ & \\
\hline HEDO_7 & A busca por este produto me deu um grande prazer. & \\
\hline \multicolumn{2}{|c|}{ Valor de compra Utilitário } & \\
\hline UTI_1 & Eu fui eficiente ao fazer esta compra. & \multirow{6}{*}{$\begin{array}{l}\text { Babin, } \\
\text { Darden } \\
\text { e Griffin } \\
(1994)\end{array}$} \\
\hline UTI_2 & Eu gastei apenas o tempo necessário para fazer esta compra. & \\
\hline UTI_3 & Eu fiz esta compra com rapidez. & \\
\hline UTI_4 & Fazer esta compra foi como cumprir uma obrigação. & \\
\hline UTI_5 & $\begin{array}{l}\text { Foi fácil fazer esta compra porque eu sabia exatamente o que } \\
\text { eu queria comprar. }\end{array}$ & \\
\hline UTI_6 & $\begin{array}{l}\text { O preço que paguei nesta compra compensou o tempo que } \\
\text { gastei. }\end{array}$ & \\
\hline \multicolumn{2}{|c|}{ Atitude Favorável ao Endividamento } & \\
\hline ENDIV_1 & $\begin{array}{l}\text { Prefiro comprar parcelado a esperar ter dinheiro para com- } \\
\text { prar à vista. }\end{array}$ & \multirow{3}{*}{$\begin{array}{l}\text { Trindade et } \\
\text { al. (2010) }\end{array}$} \\
\hline ENDIV_2 & Prefiro pagar parcelado mesmo que no total seja mais caro. & \\
\hline ENDIV_3 & $\begin{array}{l}\text { Acho normal as pessoas ficarem endividadas para pagar suas } \\
\text { coisas. }\end{array}$ & \\
\hline \multicolumn{2}{|c|}{ Atitude Contrária ao Endividamento } & \\
\hline ENDIV_4 & $\begin{array}{l}\text { Eu sei exatamente quanto devo em lojas, cartão de crédito ou } \\
\text { banco. }\end{array}$ & \multirow{3}{*}{$\begin{array}{l}\text { Trindade et } \\
\text { al. (2010) }\end{array}$} \\
\hline ENDIV_5 & É melhor primeiro juntar dinheiro e só depois gastar. & \\
\hline ENDIV_6 & $\begin{array}{l}\text { As pessoas ficariam desapontadas comigo se soubessem que } \\
\text { tenho dívida. }\end{array}$ & \\
\hline \multicolumn{2}{|c|}{ Endividamento } & \\
\hline DIV & Eu gasto mais do que ganho. & \\
\hline
\end{tabular}

Fonte: os autores. 
Os dados foram analisados com o auxílio do software Statistical Package for the Social Sciences (SPSS) versão 18.0, módulos de estatística descritiva, análise fatorial.

Um survey foi conduzido com os consumidores de dois locais distintos: em uma feira livre e em um pequeno estabelecimento de varejo. A pesquisa realizada em uma grande feira livre da capital cearense foi aplicada a uma amostra de natureza não probabilística por conveniência de 301 indivíduos. Uma amostra probabilística representativa da feira não seria possível, considerando que não existe nenhuma informação documentada sobre o número de consumidores do lugar. Os questionários foram aplicados no decorrer de vários finais de semana, durante os meses de janeiro a março de 2013, no período das 7 às 13 horas, período de maior afluência de público. Os pesquisadores, que inicialmente conheciam o local, visitaram-no com anterioridade para sentir qual seria a melhor forma de realizar a pesquisa. No pré-teste foi constatado que o questionário seria de difícil aplicação, considerando-se a pouca receptividade das pessoas. Para melhorar a resposta do público, optou-se por fornecer um incentivo às pessoas que respondessem. Foi oferecido um lanche, o qual era consumido após o preenchimento do questionário.

No estabelecimento de pequeno varejo, o estudo pesquisou uma amostra de natureza não probabilística por conveniência de 227 indivíduos, uma vez que não se possuía dados precisos sobre o número de clientes do local. Os questionários foram aplicados no decorrer de várias semanas, durante os meses de janeiro a março de 2013, no período das 7 às 18 horas. No pré-teste foi constatado que, diferente do que se verificou com os frequentadores da feira livre, os consumidores do pequeno varejo não apresentaram maiores resistências para responder ao questionário.

Quanto à escolha dos locais de pesquisa, uma observação deve ser feita. Com o objetivo de se conduzir o survey com uma amostra que pudesse representar a população de baixa renda da cidade de Fortaleza, foram escolhidos dois ambientes marcadamente frequentados por consumidores menos abastados. O primeiro, a feira da Parangaba, maior centro popular de comércio da cidade, é visitado, principalmente, por consumidores de menor poder aquisitivo (MENEZES, 2005). No segundo local, um pequeno varejo da periferia de Fortaleza; a aplicação do survey foi, por fim, consentida pelos proprietários após a recusa de proprietários de outros estabelecimentos. 


\section{ANÁLISE DOS RESULTADOS}

Responderam ao questionário 528 pessoas, sendo 342 homens $(64,8 \%)$ e 186 mulheres (35,2\%), com idades que flutuavam entre 14 e 80 anos, com média de 38 anos. Em relação à renda familiar mensal, medida em salários mínimos, 50\% dos entrevistados têm uma renda de até três salários, sendo a média salarial familiar, excluindo-se os outliers, de quatro salários. O quartil mais pobre tem uma renda de até dois salários, enquanto o quartil mais rico possui uma renda maior do que cinco salários. Em relação ao grau de instrução, 16,7\% não têm ensino fundamental completo, $7 \%$ não têm ensino médio completo, $42,8 \%$ declararam ter ensino médio completo e somente $11,4 \%$ completaram o ensino superior.

Quanto às respostas dos consumidores referentes às variáveis de pesquisa, foram extraídas as médias do somatório das questões que compõem o valor de consumo hedônico e utilitário. Com efeito, os resultados revelam que ambas as dimensões apresentaram valores similares e superiores à média, corroborando as pesquisas de Bardhi e Arnould (2005) e Lopes et al. (2010). A dimensão hedônica de consumo atingiu a uma média de 5,28 entre os respondentes, enquanto o valor de consumo utilitário alcançou um valor ligeiramente maior, 5,40.

Do mesmo modo, ao se averiguar a frequência do valor de compra predominante entre os visitantes, observa-se que não há predominância de nenhum valor de compra, porquanto os indivíduos que apresentam uma dimensão hedônica de compra positiva constituem $64 \%$ do total de entrevistados, enquanto $64,2 \%$ dos pesquisados possuem uma dimensão utilitária de compra positiva. Deve-se salientar, dessa forma, a proximidade com a qual os dois valores de compra se apresentaram nos indivíduos, uma vez que os construtos alcançaram percentagens similares, indicando haver dualidade no comportamento de compra dos consumidores, conforme aduzem as pesquisas de Bardhi e Arnould (2005) e Lopes et al. (2010).

Quanto à verificação dos construtos referentes ao endividamento, observouse que a maior parte dos entrevistados não possui atitude favorável ao endividamento $(55,9 \%)$. Contudo, a maioria dos entrevistados evidenciou que se endivida de fato (76,8\%). Conforme indicam os resultados, ressalta-se que, além de possuírem uma orientação à compra hedônica um pouco maior, indicando uma lógica dotada de menor racionalidade, os consumidores de baixa renda demonstraram passividade frente ao endividamento, corroborando as acepções de Caplovitz (1963) e Karnani (2007).

Juntamente com a análise descritiva, foi realizada uma análise fatorial confirmatória com os dados coletados. Para isso, foi utilizado o modelo de dois 
passos proposto por Anderson e Gerbing (1988), o qual indica que se deve realizar primeiramente o modelo de mensuração para depois executar o modelo estrutural. Inicialmente, foram analisados os resultados obtidos por meio do modelo de mensuração, que revelou índices satisfatórios. Os indicadores referentes ao modelo teórico são expostos na Tabela 1, a seguir.

Tabela 1- Medidas de ajuste do modelo teórico

\begin{tabular}{lllllll}
\hline Modelo Teórico & GFI & AGFI & RMSEA & TLI & NFI & CFI \\
\hline Valores das medidas de ajuste & 0,898 & 0,871 & 0,069 & 0,806 & 0,779 & 0,830 \\
\hline Fonte: os autores. & & & & & &
\end{tabular}

Como é possível visualizar na Tabela 1, nenhum dos indicadores, GFI goodness of fit index - (0,898), AGFI - adjusted goodness of fit index - (0,871), TLI Tucker-Lewis index - $(0,806)$, NFI - normed fit index - $(0,779)$ e CFI - comparative fit index - $(0,830)$, obtiveram valores considerados ideais, maiores de 0,9 (HAIR et al., 2009; TABACHNICK; FIDELL, 2011; BYRNE, 2013). Os índices GFI e AGFI, contudo, revelaram-se aceitáveis, porquanto alcançaram valores superiores a 0,8 (COTE, 2001). Igualmente, o RMSEA mostrou-se abaixo do limite máximo tolerável $(0,069)$. O índice CMIN/DF $(3,474)$ também atingiu valor satisfatório (SCHUMACKER; LOMAX, 2004).

Cabe destacar que, possivelmente, os valores não satisfatórios alcançados pelos indicadores de ajuste do modelo teórico foram influenciados, provavelmente, pela pouca solidez do construto atitude contrária ao endividamento, uma vez que a variável latente não apresentou índices aceitáveis ao se auferir a sua confiabilidade composta $(0,35)$ e a variância extraída (25,38\%) (HAIR et al., 2009). Por outro lado, as demais variáveis latentes, valor de consumo hedônico $(0,83 ; 41,62 \%)$, valor de consumo utilitário $(0,71 ; 31,93 \%)$ e a atitude favorável ao endividamento $(0,74$; 49,02\%) apresentaram confiabilidade satisfatória, ao passo que apenas o construto atitude favorável ao endividamento alcançou valores próximos a 0,5 ao se analisar a variância extraída (HAIR et al., 2009; TABACHNICK; FIDELL, 2011). Contudo, mesmo sendo apresentados valores não aceitáveis, os construtos serão mantidos, uma vez que há suporte teórico que sustente sua permanência (TONI; MAZZON, 2014).

Cumpre salientar, contudo, que tomar como verdadeiras as medidas de qualidade de ajuste de um modelo se observando seus indicadores ultrapassam valores de referência não é uma norma inquestionável e infalível. Os modelos teóricos reagem de forma diferenciada a depender da amostra da pesquisa, bem 
como dos vários tipos de medidas de adequação, formas de distribuição, etc. (HU; BENTLER, 1995).

Deve-se ressaltar, todavia, em razão da à inobservância de estudos anteriores relevantes que relacionassem os construtos examinados no modelo erigido neste estudo, não há referências nas quais seja possível realizar comparações consistentes. Destarte, o arquétipo teórico aqui construído, à guisa de pesquisa exploratória, mostra-se relevante para se confrontar com futuros modelos que pretendam lançar luz sobre as relações causais perquiridas e adaptar as escalas utilizadas para pesquisas com indivíduos de baixa renda, uma vez que, considerando a originalidade do modelo teórico proposto, não há evidências empíricas anteriores que possibilitem comparações efetivas. Embora amplamente propaladas, ademais, as escalas utilizadas neste estudo, em destaque a que aufere a atitude contra endividamento, não mostraram solidez teórica, porquanto não tenham alcançado coeficientes aceitáveis nos testes estatísticos realizados. Assim, entende-se que o modelo, porquanto, não apresenta todos os indicadores de ajuste satisfatórios, suscita amadurecimento, advindo de aperfeiçoamento teórico ou de novos estudos empíricos (HU; BENTLER, 1995; KLINE, 2005).

Embora haja apenas uma variável para a explicação do construto endividamento, Bergkvist e Rossiter (2007) aduzem ser possível a mensuração de uma variável latente com apenas uma questão sem prejuízos ao modelo teórico erigido, contanto que o objeto de análise seja claro e não exija grandes elucubrações por parte dos respondentes; como observado no construto.

Seguindo a análise, foi desenhado o modelo por meio dos aportes teóricos levantados pela literatura, com o intuito de se iniciar a etapa de verificação das hipóteses. Foram observadas as relações causais entre as variáveis latentes exógenas valor de consumo hedônico e utilitário - e as variáveis endógenas - atitude favorável e contra o endividamento e endividamento. Dessa forma, foram testadas as hipóteses H1, H2, H3 e H4, como aduz o Esquema 2, a seguir: 
Esquema 2 - Estimações padronizadas do modelo teórico inicial

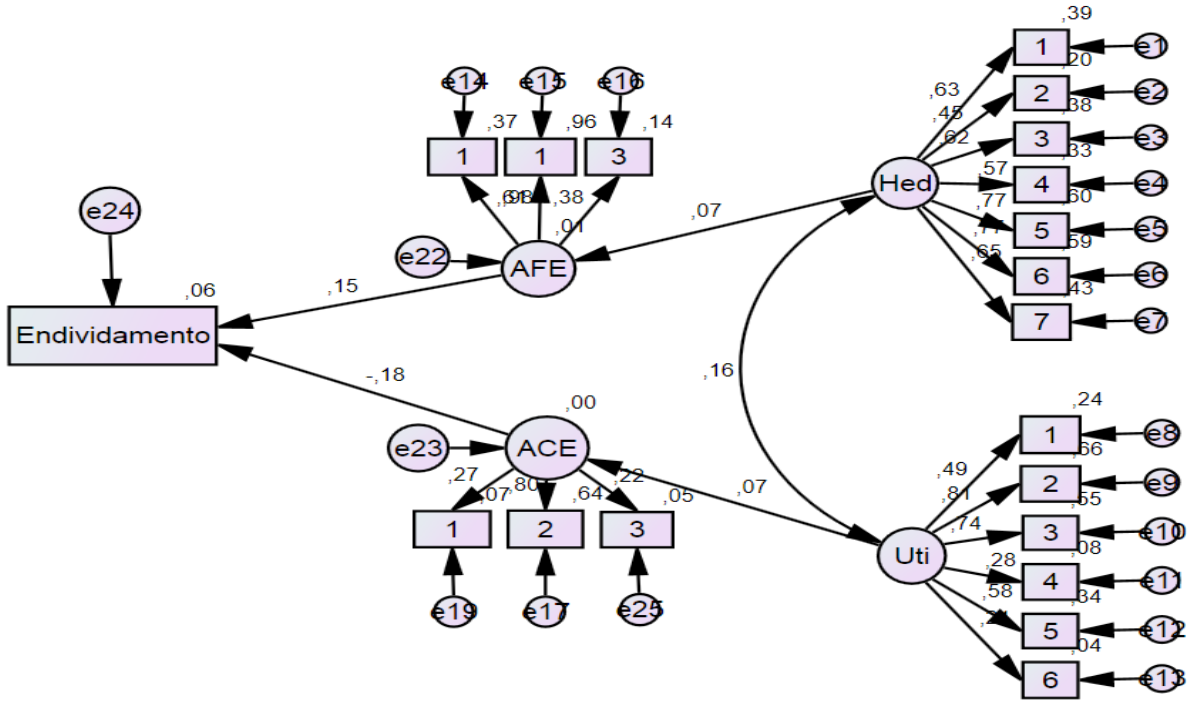

Fonte: os autores.

Por conseguinte, foram realizados os testes de hipóteses do diagrama de caminhos do modelo estrutural, visualizadas na Tabela 2 .

Tabela 2 - Testes de hipótese do modelo teórico

\begin{tabular}{lllllll}
\hline Hi & Caminhos Estruturais & $\begin{array}{l}\text { Coeficien- } \\
\text { tes não } \\
\text { Pad. (b) }\end{array}$ & Erros & $\begin{array}{l}\text { Coefi- } \\
\text { cientes } \\
\text { Pad. }(\beta)\end{array}$ & P & Resultado \\
\hline H1 & $\begin{array}{l}\text { Valor Hedônico } \rightarrow \text { Atitu- } \\
\text { de Favorável }\end{array}$ & 0,086 & 0,057 & 0,074 & 0,133 & Rejeitada \\
H2 & $\begin{array}{l}\text { Valor Utilitário } \rightarrow \text { Atitu- } \\
\text { de Contrária }\end{array}$ & 0,137 & 0,124 & 0,066 & 0,270 & Rejeitada \\
H3 & $\begin{array}{l}\text { Atitude Favorável } \rightarrow \\
\text { Endividamento }\end{array}$ & 0,243 & 0,070 & 0,154 & $0,000^{\star \star}$ & $\begin{array}{l}\text { Corrobo- } \\
\text { rada }\end{array}$ \\
H4 & $\begin{array}{l}\text { Atitude Contrária } \rightarrow \\
\text { Endividamento }\end{array}$ & $-0,275$ & 0,147 & $-0,184$ & $0,062^{\star}$ & $\begin{array}{l}\text { Corrobo- } \\
\text { rada }\end{array}$ \\
\hline
\end{tabular}

Fonte: os autores.

${ }^{\star}$ Significante a $10 \% ;{ }^{\star \star}$ Significante a $1 \%$.

De acordo com os resultados obtidos por intermédio do teste de hipóteses, observa-se que somente duas das hipóteses teóricas levantadas a priori (H3 e H4) foram corroboradas. Salienta-se, ademais, que apenas a hipótese H3 alcançou significância a 1\%. Embora as hipóteses H1 e H2, as quais aduzem que os valores 
de consumo hedônico e utilitário possuem influência significante sobre as atitudes favorável e contra o endividamento, tenham sido refutadas, deve-se reiterar o fraco ajuste matemático do modelo teórico levantado na literatura, o que impediu uma análise rigorosa das hipóteses inicialmente propostas.

Cabe observar, no entanto, que as relações entre as variáveis latentes testadas no modelo teórico não haviam sido anteriormente observadas. Dessa forma, há de se analisar mais profundamente as relações de causalidade entre os construtos do modelo para se alcançar resultados adequados.

\section{1 MODELO TEÓRICO REESPECIFICADO}

Considerando-se que o modelo teórico construído em um primeiro momento raramente apresenta resultados satisfatórios, é justificável que se realizem alterações no modelo inicial com o intuito de melhorá-lo em relação tanto aos testes estatísticos que indicam o seu ajuste quanto à melhora no arcabouço teórico apresentado (MACCALLUM, 1995; BAUMGARTNER; HOMBURG, 1996; KLINE, 2005; BYRNE, 2013).

Cumpre reiterar que, em razão da originalidade do arquétipo teórico erigido inicialmente, não há referências relevantes na literatura que utilizem os construtos desta pesquisa, nas quais seja possível realizar comparações consistentes. Dessa forma, com o intuito de melhorar o modelo teórico inicial e obter mais informações das relações entre os construtos, optou-se por segmentar o modelo em dois: no primeiro, são relacionados os construtos valor de compra hedônico, atitude favorável ao endividamento e endividamento; no segundo, são associados os construtos valor de compra utilitário, atitude contrária ao endividamento e endividamento. Como realizado no estudo de Lopes et al. (2000), também foram excluídas as questões U4 e U6 do construto valor de consumo utilitário, por apresentar cargas fatores abaixo de 0,5 (HAIR et al. 2009). Após as alterações promovidas, observou-se uma melhoria no indicador de confiabilidade composta do construto $(0,75)$.

Por conseguinte, para validar os novos modelos teóricos propostos, foram obtidas as medidas de ajuste do primeiro modelo, que relaciona o valor de consumo hedônico com a atitude favorável ao endividamento e o endividamento de fato, visualizadas na Tabela 4, a seguir. Vale destacar que todas as medidas obtidas no modelo de mensuração alcançaram valores satisfatórios. 
Tabela 4 - Medidas de ajuste do primeiro modelo teórico reespecificado

\begin{tabular}{lllllll}
\hline Modelo Teórico & GFI & AGFI & RMSEA & TLI & NFI & CFI \\
\hline Valores das medidas de ajuste & 0,981 & 0,967 & 0,039 & 0,976 & 0,963 & 0,983 \\
\hline Fonte: os autores
\end{tabular}
Fonte: os autores.

Como é possível observar na Tabela 3, todos os indicadores atingiram índices satisfatórios, uma vez que o RMSEA ficou abaixo de 0,08 e as demais medidas alcançaram valores acima de 0,9 (HAIR et al., 2009; TABACHNICK; FIDELL, 2011; BYRNE, 2013). O índice CMIN/DF também atingiu a um valor satisfatório, porquanto tenha apresentado valor inferior a 5 e superior a $1(1,82)$ (SCHUMACKER; LOMAX, 2004).

Considerando-se o ajuste matemático do primeiro modelo teórico reespecificado, um diagrama de caminhos foi construído com o intuito de se iniciar a etapa de verificação das hipóteses. No Esquema 3, a seguir, é possível observar o primeiro modelo teórico reespecificado onde se encontram todas as relações propostas nas hipóteses levantadas na etapa de pesquisa bibliográfica.

Esquema 3 - Estimações padronizadas do primeiro modelo reespecificado

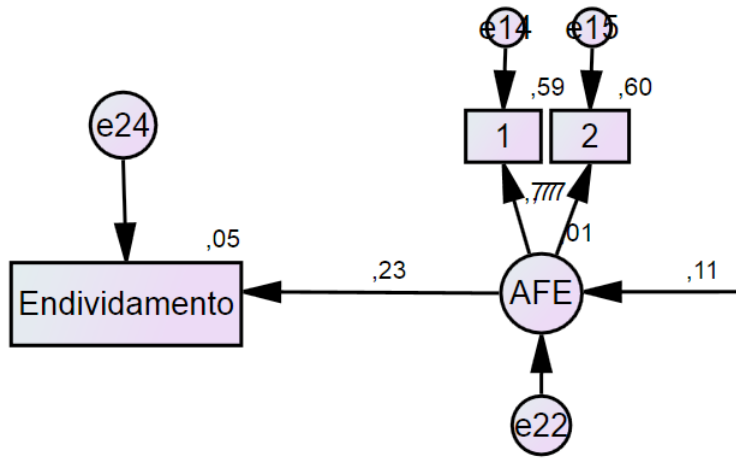

Fonte: os autores.

Ato contínuo, as medidas de ajuste do segundo modelo, que relaciona o valor de consumo utilitário com a atitude contrária ao endividamento e o endividamento de fato, foram obtidas e podem ser visualizadas na Tabela 4, a seguir. Bem como ocorreu com o primeiro modelo, todas as medidas obtidas no modelo de mensuração coincidiram com os valores alcançados pelo modelo teórico reespecificado. 
Tabela 5 - Medidas de ajuste do modelo teórico reespecificado

\begin{tabular}{lllllll}
\hline Modelo Teórico & GFI & AGFI & RMSEA & TLI & NFI & CFI \\
\hline Valores das medidas de ajuste & 0,978 & 0,953 & 0,064 & 0,921 & 0,931 & 0,951 \\
\hline
\end{tabular}
Fonte: os autores.

Com base na análise da Tabela 4, todos os indicadores atingiram índices satisfatórios (HAIR et al., 2009; BYRNE, 2013). Da mesma forma, o índice CMIN/DF também alcançou valor satisfatório $(3,168)$, inferior a 5,0 e superior a 1 (SCHUMACKER; LOMAX, 2004).

Uma vez constatado o ajuste do segundo modelo reespecificado, um diagrama de caminhos foi desenhado com o objetivo de se verificar as hipóteses de pesquisa. As relações entre os construtos são evidenciadas o Esquema 4, a seguir:

Esquema 4 - Estimações padronizadas do segundo modelo reespecificado

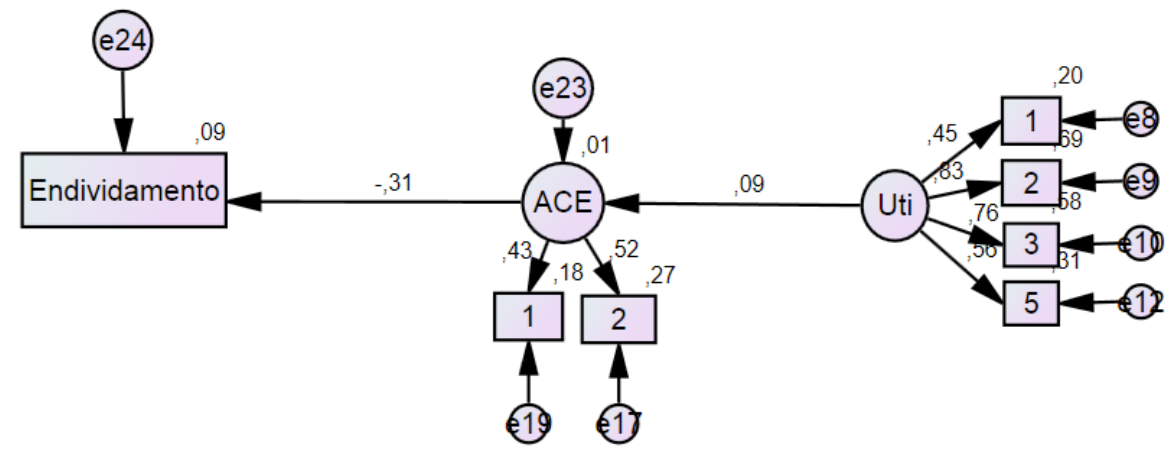

Fonte: os autores.

Ato contínuo, foram realizados os testes de hipóteses do diagrama de caminhos do novo modelo estrutural proposto, conforme demonstrado na Tabela 5, a seguir: 
Tabela 5 - Testes de hipótese dos modelos teóricos reespecificados

\begin{tabular}{lllllll}
\hline Hi & Caminhos Estruturais & $\begin{array}{l}\text { Coeficientes } \\
\text { não Pad. (b) }\end{array}$ & $\begin{array}{l}\text { Erros } \\
\text { Coefi- } \\
\text { cientes } \\
\text { Pad. }(\beta)\end{array}$ & P & Resultado \\
\hline H1 & $\begin{array}{l}\text { Valor Hedônico } \rightarrow \text { Atitu- } \\
\text { de Favorável }\end{array}$ & 0,171 & 0,085 & 0,113 & $0,045^{\star}$ & $\begin{array}{l}\text { Corrobo- } \\
\text { rada }\end{array}$ \\
H2 & $\begin{array}{l}\text { Atitude Favorável } \rightarrow \\
\text { Endividamento }\end{array}$ & 0,288 & 0,069 & 0,231 & $0,000^{\star \star}$ & $\begin{array}{l}\text { Corrobo- } \\
\text { rada }\end{array}$ \\
H3 & $\begin{array}{l}\text { Valor Utilitário } \rightarrow \text { Atitude } \\
\text { Contrária }\end{array}$ & 0,131 & 0,111 & 0,090 & 0,242 & Refutada \\
H4 $\begin{array}{l}\text { Atitude Contrária } \rightarrow \\
\text { Endividamento }\end{array}$ & $-0,715$ & 0,251 & $-0,308$ & $0,005^{\star \star}$ & $\begin{array}{l}\text { Corrobo- } \\
\text { rada }\end{array}$ \\
\hline
\end{tabular}

ॠ Significante a $5 \%$; ${ }^{\star \star}$ Significante a $1 \%$.

Fonte: os autores.

Ao se analisar os resultados revelados pelo teste de hipóteses do diagrama de caminhos dos modelos teóricos reespecificados, observa-se que as hipóteses H1, H2 e H4 foram corroboradas, enquanto a hipótese H3 foi refutada.

A relação entre o valor hedônico de consumo e a atitude favorável ao endividamento, diferentemente do que se obteve no modelo teórico inicial, foi significante $(p=0,045)$ e positiva $(\square=0,113)$. Os resultados obtidos vão ao encontro das suposições teóricas inicialmente levantadas na literatura (LIVINGSTONE; LUNT, 1992; DENEGRI, 2007; TRINDADE et al., 2010), uma vez que revelam que o valor de compra hedônico apresentado pelos indivíduos pertencentes à baixa renda representaria uma maior inclinação ao endividamento. Do mesmo modo, quanto à confirmação da hipótese $\mathrm{H} 2$, observa-se que a relação entre a atitude favorável ao endividamento e o endividamento foi significante $(\mathrm{p}=0,000)$ e positiva $(\square=0,231)$, indicando que, de fato, endividam-se os indivíduos que apresentam inclinações à dívida.

Por outro lado, a hipótese H3, que evidencia a relação causal entre o valor de consumo utilitário e a atitude contrária ao endividamento, foi refutada $(p=0,242)$. Tal resultado indica que, embora o consumidor apresente uma destacada dimensão utilitária de consumo, ou seja, suas compras com pragmatismo e eficiência econômica, não significa que possui uma atitude contrária ao endividamento. Em contraste, a H4, a qual aduz ser negativa e significante a relação entre a atitude contrária ao endividamento e o endividamento, foi corroborada $(p=0,005 ; \beta=-0,308)$; devese salientar que a relação apresentou significância a $1 \%$, diferentemente do que foi revelado no modelo teórico inicial. Dessa forma, os consumidores que apresentam atitude contrária ao endividamento não demonstram complacência ao endividamento. 
Cumpre reiterar, contudo, que a relação causal entre os construtos valor de compra hedônico e atitude favorável ao endividamento não havia sido perscrutada anteriormente na literatura. No entanto, uma vez que tais construtos se relacionam a fatores em comum, como materialismo, consumismo, compra por prazer e consumo simbólico, as variáveis foram relacionadas. De forma semelhante, porquanto apresentavam similitudes teóricas, foram relacionados os construtos valor de consumo utilitário e atitude contrária ao endividamento, pragmatismo, eficiência econômica, entre outros.

\section{CONSIDERAÇÕES FINAIS}

O propósito central de analisar, em uma feira livre e em um pequeno varejo, os valores de compra hedônico e utilitário e a conduta financeira dos consumidores de baixa renda, bem como a influência de tais valores sobre a conduta financeira desses indivíduos, foi alcançado.

Os resultados demonstraram que os indivíduos pertencentes a estratos menos abastados possuem valor de consumo híbrido, uma vez que apresentam uma lógica tanto hedônica quanto utilitária de consumo; contudo, tais consumidores demonstraram possuir a dimensão simbólica de compra como predominante. Da mesma forma, deve-se destacar que a maioria dos pesquisados se endividam, o que pode indicar a influência da limitação financeira no endividamento dos indivíduos.

Por meio da análise das relações causais entre os construtos constituintes do modelo inicial erigido da literatura, observou-se que as hipóteses referentes aos valores de compra propostas foram refutadas. Contudo, cabe destacar que, além do construto atitude contrária ao endividamento não ter apresentado um índice de confiabilidade satisfatório, o arquétipo construído não alcançou valores de ajuste ideais, demonstrando, além de uma frágil sustentação teórica, um baixo rigor científico das escalas de atitude à dívida utilizadas.

Dessa forma, após a reespecificação do modelo teórico inicial, estruturado a partir das acepções levantadas na literatura atinente ao tema, foi possível observar mais claramente a relação existente entre os valores de consumo hedônico e utilitário, a atitude favorável ao endividamento e ao endividamento de fato. De acordo com os resultados obtidos, conclui-se que a presença hegemônica do valor de consumo hedônico em um indivíduo indica mais eficazmente se ele de fato se endivida, uma vez que o exame das relações entre os construtos revela uma influência significante do valor hedônico sobre a atitude favorável ao endividamento. Por outro lado, o 
construto valor utilitário não apresentou influência significante sobre a atitude contrária ao endividamento. Destarte, um consumidor que apresente uma destacada dimensão de compra hedônica, ou seja, que assume um estilo de vida, hábitos de uso de dinheiro, comportamento em relação ao risco, valores e posturas de compra menos austeras, de fato possui maior tendência a se endividar.

De acordo com os resultados obtidos, conclui-se que associar o fenômeno do endividamento a fatores exclusivamente econômicos, como a limitação da renda, nesse caso, é uma abordagem limitada. A baixa renda é uma condição agravante da dívida, mas não a causadora. Os resultados alcançados indicam que indivíduos com baixo poder aquisitivo se endividam, principalmente, por apresentarem características psicológicas que orientam o comportamento em relação ao risco, hábitos de uso do dinheiro, estilo de vida, entre outros, características moldadas pela dimensão hedônica de compra.

Logo, é preciso que se ressalte que as políticas de massa que buscam reduzir o endividamento com tentativas de redução do crédito, oferta de cursos para se ampliar a educação e o planejamento financeiro, entre outros, não atingem o cerne da questão do endividamento. Por outro lado, tomam a causa pelo efeito ao se concentrarem em fatores que possuem efeito de potencializar, mas não de gerar o endividamento.

Como limitações ao estudo, tem-se o fato de que, embora o estudo tenha sido realizado com mais de 500 respondentes, a pesquisa não se caracteriza como uma amostragem probabilística. Outro fator limitante da pesquisa foi o fato de ter sido realizada somente em dois locais, embora se tenha utilizado o critério de representatividade para a escolha dos locais onde foi aplicado o estudo, pois o fato de não haver dados complementares para triangulação contribui para que relativa cautela seja tomada no caso de generalizações dos achados da presente pesquisa.

Para pesquisas futuras, indica-se o estudo de locais onde haja maior formalidade, como shopping centers, por exemplo, contanto que frequentadores pertençam, predominante, a camadas menos abastadas da população. Um estudo comparativo entre os resultados levantados neste trabalho e os colhidos em mercados formais seria relevante para esclarecer os padrões de consumo na baixa renda.

\section{REFERÊNCIAS}

ANDERSON, J. C.; GERBING, D. W. Structural equation modeling in practice: a review and recommended two-step approach. Psychological Bulletin, v. 103, p. 411-23, 1988. 


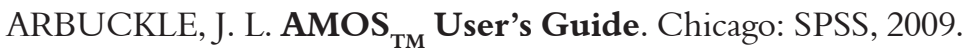

ASSOCIAÇÃO BRASILEIRA DE EMPRESAS DE PESQUISA. Critério de classificação econômica Brasil. 2009. Disponível em: < http://www.abep.org/ novo/Content.aspx?ContentI D=301>. Acesso em: 25 jun. 2014.

BABIN, B. J.; DARDEN, W. R.; GRIFFIN, M. Work and/or Fun: Measuring Hedonic and Utilitarian Shopping Value. The Journal of Consumer Research, v. 20, n. 4, p. 644-656, 1994.

BARDHI, F.; ARNOULD, E. J. Thrift shopping: combining utilitarian thrift and hedonic treat benefits. Journal of Consumer Behaviour, v. 4, n. 4, p. 223-233, 2005.

BARROS, C.; ROCHA, E. Lógica de consumo em um grupo das camadas populares: uma visão antropológica de significados culturais. In: ENCONTRO NACIONAL DA ASSOCIAÇÃO NACIONAL DOS PROGRAMAS DE PÓSGRADUAÇÃO EM ADMINISTRAÇÃO, 21., 2007, Rio de Janeiro. Anais... Rio de Janeiro: EnANPAD, 2007.

BATRA, R.; AHTOLA, O. Measuring the hedonic and utilitarian sources of consumer attitudes. Marketing Letters, v. 2, n. 2, p. 159-170, 1991.

BAUMGARTNER, H.; HOMBURG, C. Application of structural equation modeling in marketing and consumer research: a review. International Journal of Research in Marketing, v. 13, n. 2, p. 139-161, Apr. 1996.

BAURDILLARD, J. A sociedade de consumo. Lisboa: Edições 70, 2011.

BERGKVIST, L.; ROSSITER, J. R. The Predictive Validity of Multiple-Item Versus Single-Item Measures of the Same Constructs. Journal of Marketing Research, v. 44 (May), p. 175-184, 2007.

BOURDIEU, P. A distinção: crítica social do julgamento. 2 ed. Porto Alegre: Zouk, 2011.

BYRNE, B. M. Structural equation modeling with AMOS: Basic concepts, applications, and programming. New York: Routledge, 2013.

CAPLOVITZ, D. The poor pay more. New York: Free Press, 1963.

CENTRO DE EXCELÊNCIA EM VAREJO DA FUNDAÇÃO GETÚLIO VARGAS. 2008. Definição de Baixa Renda. Disponível em: < http://cev.fgv.br/ programa-baixa-renda-artigos >. Acesso em: 25 jun. 2014. 
COTE, J. Structural equations modeling: improving model fit by correlating errors. Journal of Consumer Psychology, v. 10, n. 2, p. 83-100, 2001.

DEAN, L. R. et al. Debt begets debt: examining negative credit card behaviors and other forms of consumer debt. Journal of Financial Service Professionals, v. 67, n. 2, p. 72-84, 2013.

DENEGRI, M. Introducción a la Psicología Económica. Bogotá: PSICOM Editores, 2007.

HAIR, J. F. et al. Análise Multivariada de Dados. 6. ed. Porto Alegre: Bookman, 2009.

HAMMOND, A. L. et al. The next four billion: market size and business strategy at the base of the pyramid. Washington: World Resources Institute and International Finance Corporation, 2007. Disponível em: <http://pdf.wri.org/ n4b_full_text_lowrez.pdf>. Acesso em: 12 jan. 2013.

HAUSMAN, A. A multi-method investigation of consumer motivations in impulse buying behavior. Journal of Consumer Marketing, v. 17, n. 5, p. 403426, 2000.

HEMAIS, M. W.; CASOTTI, L. M.; ROCHA, E. P. G. Hedonismo e moralismo: consumo na base da pirâmide. RAM - Revista de Administração Mackenzie, v. 53, n. 2, 2013.

HILL, R. Disadvantaged consumers: an ethical approach to consumption by the poor. Journal of Business Ethics, v. 80, n. 1, p. 77-83, 2008.

HILL, R.; STEPHENS, D. Impoverished consumers and consumer behavior: the case of AFDC mothers. Journal of Macromarketing, v. 17, n. 2, p. 32-48, 1997.

HOLBROOK, M.; HIRSCHMAN, E. The experiential aspects of consumption: consumer fantasies, feelings, and fun. Journal of Consumer Research, v. 9, n. 2, p. 132-140, 1982.

HU, L.; BENTLER, P. M. Evaluating model fit. In: HOYLE, R. H. (Ed.). Structural equation modeling: concepts, issues, and applications. Thousand Oaks: Sage Publications, 1995.

INSTITUTO BRASILEIRO DE GEOGRAFIA E ESTATÍSTICA. Síntese de indicadores sociais: uma análise de condições de vida da população brasileira. 2009. Disponível em: < http://www.ibge.gov.br/home/estatistica/populacao/ condicaodevida/indicadoresminimo/sinteseindicsociais2009/indic_sociais2009. pdf > . Acesso em: 25 jun. 2014. 
JOO, S.; GRABLE, J. An exploratory framework of the determinants of financial satisfaction. Journal of Family and Economic Issues. v. 25, n. 1, p. 25-50, 2004.

KARNANI, A. The mirage of marketing to the bottom of the pyramid. How the private sector can help alleviate poverty. California Management Review, v. 49, n. 4, p. 90-111, 2007.

KIDWELL, B.; TURRISI, R. An examination of college student money management tendencies. Journal of Economic Psychology, v. 25, p. 601-616, 2004.

KLINE, R. B. Principles and practice of structural equation modeling. 2. ed. New York: The Guilford Press, 2005.

LEGGE, J.; HEYNES, A. Beyond Reasonable Debt: A Background Report on the Indebtedness of New Zealand Families. Social Policy Journal of New Zealand, v. 35, p. 27-42, 2009.

LIPOVETSKY, G. A felicidade paradoxal: ensaios sobre a sociedade de hiperconsumo. São Paulo: Companhia das Letras, 2007.

LIPOVETSKY, G.; SERROY, J. A cultura-mundo. Resposta a uma sociedade desorientada. São Paulo: Companhia das Letras, 2011.

LIVINGSTONE, S.; LUNT, P. K. Predicting personal debt and debt repay me: psychological, social and economic determinants. Journal of Economic Psychology, n. 13, p. 111-134, 1992.

LOPES, E. L. et al. Valores de compra hedônico e utilitário: duas aplicações no varejo especializado. In: ASSOCIAÇÃO NACIONAL DE PÓS-GRADUAÇÃO E PESQUISA EM ADMINISTRAÇÃO, 34., 2010, Rio de Janeiro. Anais... Rio de Janeiro: ANPAD, 2010.

LUSARDI, A.; MITCHELL, O. S. Baby boomer retirement security: The roles of planning, financial literacy, and housing wealth. Journal of monetary Economics, v. 54, n. 1, p. 205-224, 2007.

MacCALLUM, R. C. Model specification: procedures, strategies and related issues. In: HOYLE, R. H. (Ed.). Structural equation modeling: concepts, issues, and applications. Thousand Oaks: Sage Publications, p. 16-36, 1995.

MALHOTRA, N. K. Pesquisa de marketing. 4. ed. Porto Alegre: Bookman, 2006. 
MATTOSO, C. Classes sociais, peculiaridades na base da pirâmide e a possibilidade de esquemas classificatórios. In: ASSOCIAÇÃO NACIONAL DE PÓS-GRADUAÇÃO E PESQUISA EM ADMINISTRAÇÃO, 34., 2010, Rio de Janeiro. Anais... Rio de Janeiro: ANPAD, 2010.

MENEZES, V. As feiras-livres em Fortaleza - retrato da polissemia urbana. 2005. 130 p. Dissertação (Mestrado em Geografia)-Universidade Estadual do Ceará, Fortaleza, 2005.

NORVILITIS, J. M.; SZABLICKI, P. B.; WILSON, S. Factors influencing levels of credit-card debt in college students. Journal of Applied Social Psychology, v. 33, n. 5, p. 935-947, 2006.

PRAHALAD, C. K. The fortune at the bottom of the pyramid: eradicating poverty through profits. New Jersey: Pearson Education, 2006.

PRAHALAD, C. K.; HART, S. The fortune at the bottom of the pyramid. Strategy + Business, n. 26, p. 54-67, 2002. Disponível em: <http://www. cs.berkeley.edu/ brewer/ict4b/ Fortune-BoP.pdf> . Acesso em: 02 jun. 2011.

ROCHA, A.; SILVA, J. Inclusão social e marketing para a base da pirâmide: uma agenda de pesquisa. RAE-Eletrônica, v. 7, n. 2, 2008.

ROCHA, E. Culpa e prazer: imagens do consumo na cultura de massa.

Comunicação, Mídia e Consumo, v. 2, n. 3, p. 123-138, 2005.

ROCHA, E. Invisibilidade e revelação: camadas populares, cultura e práticas de consumo -apresentação. In: ROCHA, A; SILVA, J. (Org.). Consumo na base da pirâmide: estudos brasileiros. Rio de Janeiro: Mauad X, 2009.

SCHUMACKER, R; LOMAX, R. G. A beginner's guide to structural equation modeling. 2. ed. Mahwah: Lawrence Erlbaum Associates, 2004.

STENNING, A. et al., D. Credit, Debt, and Everyday Financial Practices: LowIncome Households in Two Postsocialist Cities. Economic Geography, v. 86, p. 119-145, 2010.

STONE, B.; MAURY, R. V. Indicators of personal financial debt using a multidisciplinary behavioral model. Journal of Economic Psychology, v. 27, n. 4, p. 543-556, 2006.

TABACHNICK, B. G.; FIDELL, L. Using multivariate statistics. 6. ed. New York: Pearson Academic, 2011. 
TONI, D; MAZZON, J. A. Teste de um modelo teórico sobre o valor percebido do preço de um produto. Revista de Administração da USP, v. 49, n. 3, p. 549$565,2014$.

TRINDADE, L. L. et al. Atitude para dívida: uma análise do comportamento feminino para o endividamento. In: SEMINÁRIOS EM ADMINISTRAÇÃO, 13., 2010, São Paulo. Anais... São Paulo: SemeAd, 2010.

VEBLEN, T. The Theory of the Leisure Class: an economic study of institutions. Macmillan: New York, 1915.

WARNER, W.; MEEKER, M.; EELLS, K. Social Class in America: a manual of procedure for the measurement of Social Status. Chicago: Science Research Associates, 1949.

WILLIAMS, C.; WINDEBANK, J. Acquiring goods and services in lower income populations: an evaluation of consumer behaviour and preferences. International Journal of Retail \& Distribution Management, v. 29, n. 1, p. 16-25, 2001.

\section{Como citar este artigo:}

GERHARD, Felipe et al. Consumo na baixa renda: influência dos valores $\leftarrow$ de compra hedônico e utilitário no endividamento. RACE, Revista de Z Administração, Contabilidade e Economia, Joaçaba: Ed. Unoesc, v. 14, n. 2, \& p. 797-824, maio/ago. 2015. Disponível em: < http://editora.unoesc.edu.br/index. php/race >. Acesso em: dia/mês/ano.

Gerhard, F., Sousa, T. M. de P., Souza, L. L. F. de, Carvalho, H. A. de, \& Fuentes, V. L. P. (2015). Consumo na baixa renda: influência dos valores de

compra hedônico e utilitário no endividamento. RACE, Revista de Administração, Contabilidade e Economia, 14(2), 797-824. Recuperado em dia/mês/ano, de http:// editora.unoesc.edu.br/index.php/race 
